Research Article

\title{
Relationship between Brittleness Index and Crack Initiation Stress Ratio for Different Rock Types
}

\author{
Juyu Jiang $\mathbb{D},{ }^{1}$ Dong Wang $\mathbb{D}^{1},{ }^{1}$ Xinping Han, ${ }^{1}$ and Shuai $\mathrm{Di}^{2}$ \\ ${ }^{1}$ College of Mining, Liaoning Technical University, Fuxin, Liaoning 123000, China \\ ${ }^{2}$ Information Research Institute of the Ministry of Emergency Management, Beijing 100029, China \\ Correspondence should be addressed to Dong Wang; lntu_wd@163.com
}

Received 10 July 2019; Revised 22 December 2019; Accepted 10 February 2020; Published 24 April 2020

Academic Editor: Hugo Rodrigues

Copyright (C) 2020 Juyu Jiang et al. This is an open access article distributed under the Creative Commons Attribution License, which permits unrestricted use, distribution, and reproduction in any medium, provided the original work is properly cited.

\begin{abstract}
Brittleness and crack initiation stress $\left(\sigma_{\mathrm{ci}}\right)$ are important rock mechanical properties and intrinsically related to rock deformation and failure. We establish the relationship between $\sigma_{\mathrm{ci}}$ and uniaxial tensile strength $\left(\sigma_{\mathrm{t}}\right)$ based on the Griffith stress criterion of brittle failure and introduce brittleness indexes $B_{1}-B_{4}$ based on the ratio of uniaxial compressive strength $\left(\sigma_{\mathrm{c}}\right)$ to $\sigma_{\mathrm{t}}$. The crack initiation stress ratio $(K)$ is defined as the ratio of $\sigma_{\mathrm{ci}}$ to crack damage stress. The relationship between brittleness index and $K$ is obtained from laboratory mechanics tests including uniaxial compression and Brazilian splitting tests. The results show that $B_{1}$ and $B_{2}$ have an inversely proportional and variant inversely proportional relationship with $K$, respectively, whereas no apparent relationship is observed between $B_{3}$ and $B_{4}$ and $K$. The fitting of experimental data from igneous, metamorphic, and sedimentary rocks shows that $B_{1}$ and $B_{2}$ have a power and linear relationship with $K$, respectively, whereas no functional relationship is observed between $B_{3}$ and $B_{4}$ and $K$. We collected 70 different types of uniaxial compression test data for igneous, metamorphic, and sedimentary rocks and obtained laws that are consistent within each rock type. The experimental data are used to verify $K$ estimations using a specified constant $\alpha$ based on the experimental data. According to results of the limestone tests, $\alpha=3$ for $\sigma_{\mathrm{c}}<60 \mathrm{MPa}$ (high porosity), $\alpha=5$ for $60 \mathrm{MPa} \leq \sigma_{\mathrm{c}} \leq 90 \mathrm{MPa}$ (moderate porosity), and $\alpha=8$ for $\sigma_{\mathrm{c}}>90 \mathrm{MPa}$ (low porosity) as well as for igneous and metamorphic rocks. Estimates of $K$ for 127 different rock types using the newly defined brittleness index are in good agreement with the experimental results. This study provides an important new brittleness index calculation method and a simple and reliable method for estimating $K$.
\end{abstract}

\section{Introduction}

The rock brittleness index is of great significance for mining engineering, tunnel engineering, oil and gas exploration, and rock burst susceptibility and has received extensive attention in the literature. Although brittleness is one of the most important rock properties, there remains no standardized or universally accepted concept of brittleness or a measurement method that exactly defines a rock brittleness index. Morley [1] and Hetenyi [2] defined brittleness as the lack of ductility. Ramsey [3] argued that rocks are brittle when their internal cohesion is broken. The definition of brittleness itself ranges from broad descriptions, such as materials "at or only slightly beyond the yield stress" [4] and "materials that rupture or fracture with little or no plastic flow" (Glossary of Geology and Related Sciences 1960) to specific descriptions such as low elongation values, fracture failure, formation of fines, higher ratio of compressive to tensile strength, higher resilience, higher angle of internal friction, and/or formation of cracks during indentation [5]. Dozens of brittleness indexes have been proposed from different viewpoints. Hucka and Das [5] proposed brittleness indexes $B_{1}$ and $B_{2}$ from the viewpoint of the ratio of uniaxial compressive strength $\left(\sigma_{\mathrm{c}}\right)$ to tensile strength $\left(\sigma_{t}\right)$, and Altindag [6-8] proposed brittleness indexes $B_{3}$ and $B_{4}$. These indexes are calculated as follows: 


$$
\begin{aligned}
& B_{1}=\frac{\sigma_{\mathrm{c}}}{\sigma_{\mathrm{t}}}, \\
& B_{2}=\frac{\sigma_{\mathrm{c}}-\sigma_{\mathrm{t}}}{\sigma_{\mathrm{c}}+\sigma_{\mathrm{t}}}, \\
& B_{3}=\frac{\sigma_{\mathrm{c}} \sigma_{\mathrm{t}}}{2}, \\
& B_{4}=\sqrt{\frac{\sigma_{\mathrm{c}} \sigma_{\mathrm{t}}}{2}},
\end{aligned}
$$

where $\sigma_{\mathrm{c}}$ is the uniaxial compressive strength and $\sigma_{\mathrm{t}}$ is tensile strength.

From the viewpoint of stress-strain curves, Tarasov and Potvin [9] substituted the energy ratio with the elastic modulus ratio during loading and proposed brittleness indexes $B_{5}$ and $B_{6}$. Bishop [10] gave brittleness index $B_{7}$ based on the peak strength and residual strength in the stressstrain curve. Hajiabdolmajid and Kaiser [11] proposed index $B_{8}$ based on the study of Bishop [10] to determine brittleness after considering the peak and residual strain. According to strain and strain energy during loading and recovery, brittleness indexes $B_{9}$ and $B_{10}$ are summarized by Hucka and Das [5]. Aubertin et al. [12] and George [13] proposed brittleness indexes $B_{11}$ and $B_{12}$ using energy and strain, respectively. Brittleness indexes $B_{5}-B_{12}$ are defined as follows.

$$
\begin{aligned}
& B_{5}=\frac{\mathrm{d} W_{\mathrm{r}}}{\mathrm{d} W_{\mathrm{e}}}=\frac{M-E_{\mathrm{u}}}{M}, \\
& B_{6}=\frac{\mathrm{d} W_{\alpha}}{\mathrm{d} W_{\mathrm{e}}}=\frac{E_{\mathrm{u}}}{M},
\end{aligned}
$$

where $d W_{\mathrm{r}}$ is the postpeak rupture energy, $\mathrm{d} W_{\mathrm{e}}$ is the withdrawn elastic energy, $\mathrm{d} W_{\alpha}$ is the released elastic energy, $E$ is the unloading elastic modulus, and $M$ is the postpeak modulus:

$$
\begin{aligned}
& B_{7}=\frac{\tau_{\mathrm{p}}-\tau_{\mathrm{r}}}{\tau_{\mathrm{p}}}, \\
& B_{8}=\frac{\varepsilon_{\mathrm{p}}-\varepsilon_{\mathrm{r}}}{\varepsilon_{\mathrm{p}}},
\end{aligned}
$$

where $\tau_{\mathrm{p}}$ is the peak strength, $\tau_{\mathrm{r}}$ is the residual strength, $\varepsilon_{\mathrm{p}}$ is the peak strain, and $\varepsilon_{\mathrm{r}}$ is the residual strain:

$$
\begin{aligned}
B_{9} & =\varepsilon_{\mathrm{h}} / \varepsilon, \\
B_{10} & =W_{\mathrm{r}} / W,
\end{aligned}
$$

where $\varepsilon_{\mathrm{h}}$ is the reversible strain, $\varepsilon$ is the total strain, $W_{\mathrm{r}}$ is the reversible strain energy, and $W$ is the total strain energy:

$$
B_{11}=\frac{A_{2}}{A_{1}},
$$

where $A_{2}$ represents the energy given by the total area below the stress-stain curve and $A_{1}$ is the elastic energy stored in the sample, which is obtained here by using the slope of the curve at $50 \%$ of the ultimate strength:

$$
B_{12}=\varepsilon_{1}
$$

where $\varepsilon_{1}$ is the axial strain. The specimen demonstrates brittle properties when $\varepsilon_{1}<3 \%$ and plastic properties when $\varepsilon_{1}>5 \%$. When $\varepsilon_{1}$ is between $3 \%$ and $5 \%$, the specimen exhibits both brittle and plastic properties.

From a hardness test viewpoint, Honda and Sanada [14] found that crack development is a direct function of brittleness, and differences between the microindentation and macroindentation hardness values may be taken as a measure of brittleness $\left(B_{13}\right)$. The brittleness index $B_{14}$ was proposed by Lawn and Marshall [15]. J. B. Quinn and G. D. Quinn [16] studied ceramic materials and proposed brittleness index $B_{15}$ :

$$
\begin{aligned}
& B_{13}=\frac{H_{\mu}-H}{k}, \\
& B_{14}=\frac{H}{K_{\mathrm{IC}}}, \\
& B_{15}=\frac{H E}{K_{\mathrm{IC}}^{2}},
\end{aligned}
$$

where $H_{\mu}$ is the microindentation hardness, $H$ is the macroindentation hardness, $E$ is Young's modulus, $K_{\text {IC }}$ is the fracture toughness, and $k$ is a constant.

The brittleness index $B_{16}$ [17] was introduced from punch penetration tests. Copur et al. [18] performed experiments to quantify the force and brittleness index relevant to rock cutting performance. Blocks of eleven different rock samples were collected from different operating mines in Turkey and subjected to indentation tests to calculate brittleness index $B_{17}$. The results show that $B_{17}$ is moderately correlated with cutting performance and rock mechanical properties and poorly correlated with coarseness index and cutting size distribution:

$$
\begin{aligned}
& B_{16}=\frac{F_{\max }}{P}, \\
& B_{17}=\frac{P_{\mathrm{dec}}}{P_{\mathrm{inc}}},
\end{aligned}
$$

where $F_{\text {max }}$ is the maximum applied force on a rock sample, $P$ is the corresponding penetration at maximum force, $P_{\text {dec }}$ is the average force decrement period, and $P_{\text {inc }}$ is the average force increment period.

Rock brittleness indexes $B_{18}, B_{19}$, and $B_{20}$ are defined from the viewpoint of Mohr's circle and impact tests $[5,19,20]$ as follows:

$$
\begin{aligned}
& B_{18}=\sin \theta, \\
& B_{19}=S_{20}, \\
& B_{20}=q \sigma_{c},
\end{aligned}
$$

where $\theta$ is the internal friction angle, $S_{20}$ is the percentage of fines $(<11.2 \mathrm{~mm})$, and $q$ is the percentage of fines (28 mesh) formed in the Protodyakonov impact test.

Although the results of brittleness indexes are very rich, discussion on the relationship between brittleness index and 
crack initiation stress ratio $(K)$ for different rock types is rarely reported from the perspective of rock compressive strength and $\sigma_{\mathrm{t}}$. In this study, we establish the relationship between $\sigma_{\mathrm{ci}}$ and $\sigma_{\mathrm{t}}$ using fracture mechanics theory. We theoretically derive the functional relationship between brittleness indexes $B_{1}-B_{4}$ and $K$. We select igneous (e.g., granite), metamorphic (e.g., gneiss), and sedimentary (e.g., limestone) rocks for laboratory mechanical tests including uniaxial compression and Brazilian splitting tests. Rock $\sigma_{\mathrm{ci}}$ is determined using the crack volumetric strain method. Seventy uniaxial compression test data for igneous, metamorphic, and sedimentary rocks were collected to further explore the relationship between $B_{1}-B_{4}$ and $K$. We use the newly defined brittleness index to estimate $K$ from 127 different rocks types and compare the results with the experimental results. The feasibility of using $K$ to calculate the brittleness index is verified by the results presented here. This also provides a simple and reliable method for estimating $K$.

\section{Crack Initiation Mechanism of Rock under Uniaxial Compression}

Lockner [21] argued that deformation and failure is a progressive process characterized by the initiation, propagation, and coalescence of microcracks for most rock samples. Zhou et al. [22-24] and Liu et al. [25] proposed that the complete cracking process can be classified into six levels distinguishable by five characteristic stresses based on the coupled analyses of the acousto-optic-mechanical characteristics. These include (1) crack closure stress $\sigma_{\mathrm{cc}}$, (2) microcrack nucleation stress $\sigma_{\mathrm{cn}}$, (3) crack initiation stress $\sigma_{\mathrm{ci}}$, (4) crack damage stress $\sigma_{\mathrm{cd}}$, and (5) peak stress $\sigma_{\mathrm{c}}$. As shown in Figure 1, the stress-strain curve is usually divided into five stages (I-V), where $\sigma_{\mathrm{ci}}$ and $\sigma_{\mathrm{cd}}$ are the focus of rock mechanical studies [26-29]. The determination of $\sigma_{\mathrm{cd}}$ has been widely reported, namely, the axial stress corresponding to the volume strain reversal point. Martin [30] proposed a crack volumetric strain method to determine rock $\sigma_{\mathrm{ci}}$ from uniaxial or triaxial tests. The $\sigma_{\mathrm{ci}}$ corresponds to stress at the end of the horizontal section with a crack volumetric strain of zero (Figure 1). The crack volume strain $\varepsilon_{\mathrm{cv}}$ is given as follows:

$$
\varepsilon_{\mathrm{cv}}=\varepsilon_{\mathrm{v}}-\varepsilon_{\mathrm{ev}},
$$

where $\varepsilon_{\mathrm{v}}$ and $\varepsilon_{\mathrm{ev}}$ are the total volume strain and elastic volume strain, respectively.

The total volume strain is defined as follows:

$$
\varepsilon_{\mathrm{v}}=\varepsilon_{1}+2 \varepsilon_{2},
$$

where $\varepsilon_{1}$ and $\varepsilon_{2}$ are the axial and lateral strains, respectively.

The elastic volume strain is calculated as follows:

$$
\varepsilon_{\mathrm{ev}}=\frac{1-2 \nu}{E} \sigma_{1},
$$

where $\sigma_{1}$ is the axial stress, $E$ is the elastic modulus, and $v$ is Poisson's ratio in the elastic stage.

In addition, $\sigma_{\mathrm{ci}}$ can be determined as the point where volumetric strain starts to deviate from the straight line of stage II, and the two methods can be calibrated to each other.
In this study, the definition of the crack initiation stress ratio $(K)$ is introduced [31] and defined as follows:

$$
K=\frac{\sigma_{\mathrm{ci}}}{\sigma_{\mathrm{cd}}}
$$

Martin [30] and Cai et al. [31] noted that $K$ is an indicator of rock heterogeneity and texture. Low $K$ values indicate high rock heterogeneity. A total of 227 sets of uniaxial compression test data for different rock samples were collected from various literature sources [32], including 138, 53, and 36 sets from igneous, sedimentary, and metamorphic rocks, respectively. The $K$ of igneous rocks ranges from 0.4 to 0.6 , that of metamorphic rocks ranges from 0.15 to 0.6 , and that of sedimentary rocks ranges from 0.3 to 0.8 . In this study, we use the theory of fracture mechanics to study the relationship between brittleness index and $K$.

\section{Analysis of the Relationship between Brittleness Index and $K$ Value}

3.1. Brittle Rock. Under tensile loading, crack initiation often means that tensile fracture is about to occur and that $\sigma_{\mathrm{ci}}$ is very close to $\sigma_{\mathrm{t}}$. However, crack initiation is only related to lower stress under compression conditions. After $\sigma_{\mathrm{ci}}$ is exceeded, cracks begin to stably expand and additional load is required to bring the stress from $\sigma_{\mathrm{ci}}$ to $\sigma_{\mathrm{c}}$. The Griffith stress criterion is applied to crack initiation when $\sigma_{\mathrm{c}}=\sigma_{\mathrm{ci}}$, and the relationship between $\sigma_{\mathrm{c}}$ and $\sigma_{\mathrm{t}}$ is constructed according to the Griffith stress criterion, i.e., $R_{\mathrm{G}}=\sigma_{\mathrm{c}} /\left|\sigma_{\mathrm{t}}\right|=8$. Hence, Cai et al. [33] proposed using the strength ratio (equation (17) to estimate $\sigma_{\mathrm{t}}$ of the brittle rock from $\sigma_{\mathrm{ci}}$ and $\sigma_{\mathrm{c}}$, as in equation (18):

$$
\begin{aligned}
R & =R_{\mathrm{G}} \frac{\sigma_{\mathrm{c}}}{\sigma_{\mathrm{ci}}}=8 \frac{\sigma_{\mathrm{c}}}{\sigma_{\mathrm{ci}}}, \\
\left|\sigma_{\mathrm{t}}\right| & =\frac{\sigma_{\mathrm{c}}}{R}=\frac{\sigma_{\mathrm{ci}}}{8} .
\end{aligned}
$$

Based on the study of Hucka and Das [5] and Altindag [6-8], Wang et al. [34] redefined brittleness indexes $B_{1}-B_{4}$ after introducing $K$, but these study only apply to brittle rocks and equations (1)-(4) are written in the following forms:

$$
\begin{aligned}
& B_{1}=\frac{\sigma_{\mathrm{c}}}{\sigma_{\mathrm{t}}}=\frac{8 \sigma_{\mathrm{c}}}{\sigma_{\mathrm{ci}}}=\frac{8}{K}, \\
& B_{2}=\frac{\sigma_{\mathrm{c}}-\sigma_{\mathrm{t}}}{\sigma_{\mathrm{c}}+\sigma_{\mathrm{t}}}=\frac{8 \sigma_{\mathrm{c}}-\sigma_{\mathrm{ci}}}{8 \sigma_{\mathrm{c}}+\sigma_{\mathrm{ci}}}=\frac{8-K}{8+K}, \\
& B_{3}=\frac{\sigma_{\mathrm{c}} \sigma_{\mathrm{t}}}{2}=\frac{\sigma_{\mathrm{c}} \sigma_{\mathrm{ci}}}{16}, \\
& B_{4}=\sqrt{\frac{\sigma_{\mathrm{c}} \sigma_{\mathrm{t}}}{2}}=\sqrt{\frac{\sigma_{\mathrm{c}} \sigma_{\mathrm{ci}}}{16}} .
\end{aligned}
$$

3.2. Weak Rock. Cai et al. [33] argued that the mechanical behavior of sedimentary rocks differs significantly from igneous rocks, e.g., limestone, dolomite, and clay have 


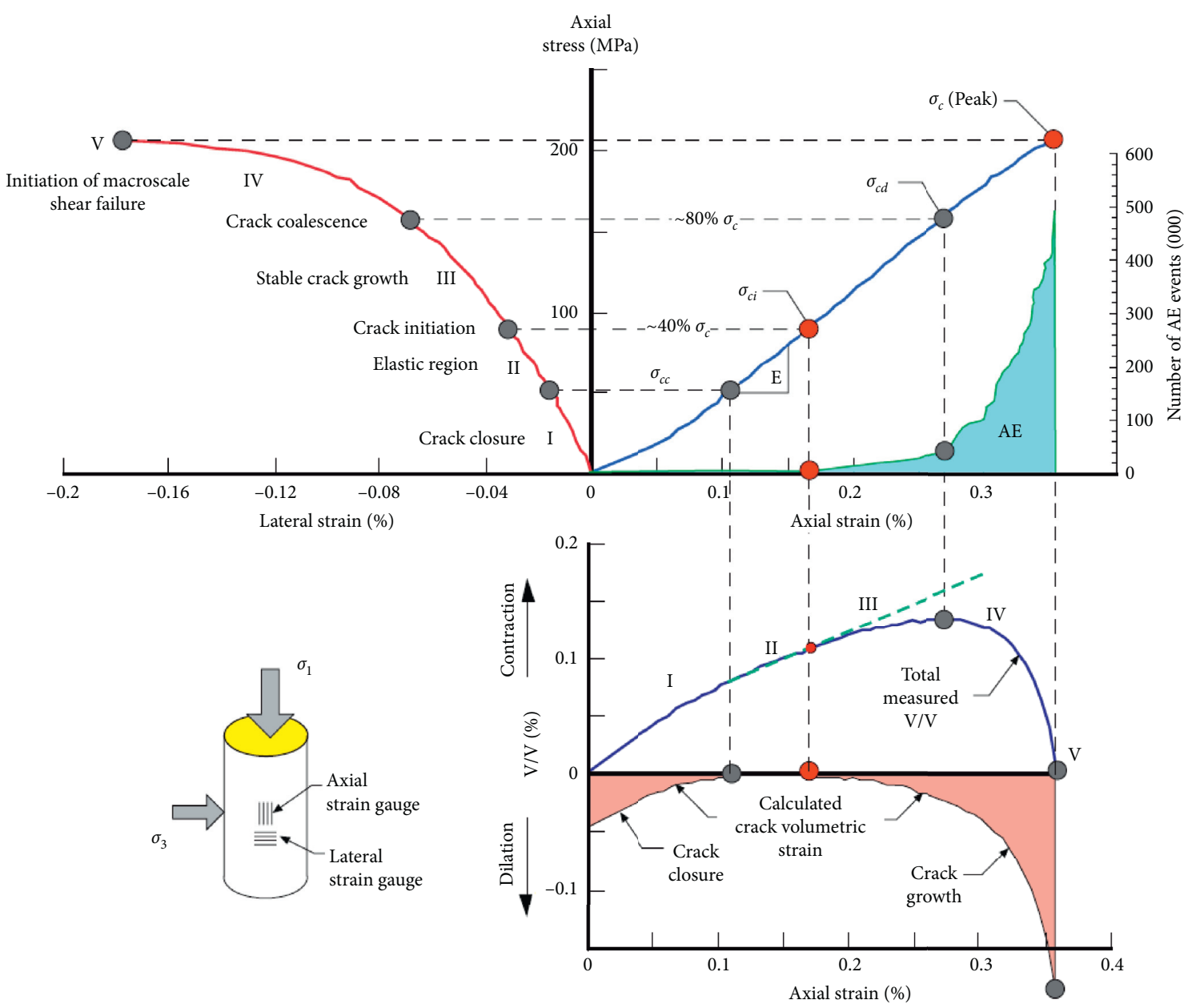

FIgURE 1: Stress-strain diagram of granite showing the stages of crack development (after [30]).

porosities higher than $20 \%$. Coviello et al. [35] showed that the strength ratio $R$ of Gravina calcarenite is 6.2, whereas Martin and Lanyon [36] reported $R$ from the Opalinus clay of only 3.2, substantially lower than the value suggested by equation (17). This error may be because the fitted HoekBrown curves overestimate $\sigma_{\mathrm{t}}$ for weak rocks [37]. Another possibility is that the clay and/or the calcite contents in these rocks are relatively high so that the Griffith crack growth fracture mechanism no longer dominates. Other fracture mechanisms (e.g., weak inclusions) may play a role in crack initiation and growth of preexisting defects [33]. Accounting for the difference of crack propagation in compression and tension, Cai et al. [33] noted that $R$ for rocks containing circular pores is as follows:

$$
R=3 \frac{\sigma_{\mathrm{c}}}{\sigma_{\mathrm{ci}}}
$$

and they further proposed $R$ for different rocks as follows:

$$
R=\alpha \frac{\sigma_{\mathrm{c}}}{\sigma_{\mathrm{ci}}}
$$

where $\alpha$ is a constant depending on the rock texture (e.g., grain size and shape), mineral content (e.g., clay and/or calcite content), and crack initiation mechanism (e.g.,
Griffith cracks or pore inclusions). Therefore, $\alpha=8$ for brittle rocks, $\alpha<8$ for porous and weak rocks, $\alpha=3$ when the pore flaw is a circular hole, $\alpha=5$ when the pore flaw is an elliptical hole, and $\alpha=3$ for a 3D spherical hole [38]. However, the determination of $\alpha$ requires further study.

Based on the above analysis, the $\sigma_{\mathrm{ci}}$ of different types of rocks can be estimated from

$$
\sigma_{\mathrm{ci}}=\alpha\left|\sigma_{\mathrm{t}}\right|
$$

Hence, equation (22) is introduced into the brittleness index formula. We redefine brittleness indexes $B_{1}-B_{4}$ for the different types of rock as follows:

$$
\begin{aligned}
& B_{1}=\frac{\sigma_{\mathrm{c}}}{\sigma_{\mathrm{t}}}=\frac{\alpha \sigma_{\mathrm{c}}}{\sigma_{\mathrm{ci}}}=\frac{\alpha}{K}, \\
& B_{2}=\frac{\sigma_{\mathrm{c}}-\sigma_{\mathrm{t}}}{\sigma_{\mathrm{c}}+\sigma_{\mathrm{t}}}=\frac{\alpha \sigma_{\mathrm{c}}-\sigma_{\mathrm{ci}}}{\alpha \sigma_{\mathrm{c}}+\sigma_{\mathrm{ci}}}=\frac{\alpha-K}{\alpha+K}, \\
& B_{3}=\frac{\sigma_{\mathrm{c}} \sigma_{\mathrm{t}}}{2}=\frac{\sigma_{\mathrm{c}} \sigma_{\mathrm{ci}}}{2 \alpha}, \\
& B_{4}=\sqrt{\frac{\sigma_{\mathrm{c}} \sigma_{\mathrm{t}}}{2}}=\sqrt{\frac{\sigma_{\mathrm{c}} \sigma_{\mathrm{ci}}}{2 \alpha} .}
\end{aligned}
$$


By identifying $\sigma_{\mathrm{ci}}$ to correctly evaluate the brittleness index of different rock types from uniaxial compression tests, the key is to identify the right fracture initiation mechanism and hence $\alpha$. In general, Griffith's constant of 8 is applicable to most brittle rocks and a large number of tests are required for other rock types. As described above, there is an intrinsic relationship between the brittleness index and $K$. The correlation is studied from indoor tests and obtained values of $\alpha$ are verified.

\section{Experimental Materials and Methods}

Rock samples used in the tests include granite, gneiss, and limestone collected from a mining site in China. Samples were cut and polished into 34 cylindrical standard test pieces $(\Phi 50 \times 100 \mathrm{~mm})$, including 13 granites, 13 gneiss, and 8 limestones. The groupings and numbers of specimens $(\Phi 50 \times 25 \mathrm{~mm})$ for the Brazilian tests are the same as those for the uniaxial compression tests. The lithology and uniformity of rock samples are mainly considered in the sampling process. Rock samples are selected to be as representative as possible to achieve realistic results. A WAW600C universal testing machine at Liaoning Technical University was used to conduct the uniaxial compression and Brazilian tests (Figure 2). The upper and lower ends of the cylindrical samples were maintained flat during preparation, and the unevenness of the two ends varied by no more than $0.05 \mathrm{~mm}$. Acoustic testing was performed prior to the start of the uniaxial compression test to eliminate anomalous rock samples. During the loading phase, axial and lateral strain was measured using an extensometer and the loading rate was maintained at $0.03 \mathrm{~mm} / \mathrm{min}$ until the peak strength was reached. The loading rate was $0.2 \mathrm{MPa} / \mathrm{s}$ for the Brazilian tests.

To study the relationship between brittleness index and $K$ for different rock types, we use a variety of functional forms (e.g., exponential, logarithmic, power, and linear) to fit the test data. A variety of functional forms are also used to fit the comprehensive data (i.e., synthesis of granite, gneiss, and limestone data) for different rock types. The functional form with the highest correlation coefficient is selected as the final fitting function to best represent the data.

4.1. Igneous Rock: Granite. Results of the granite mechanical parameters obtained from the laboratory tests are listed in Table 1. Figure 3 shows the fitting analysis of the data and that brittleness index $B_{1}$ and $K$ have a power function relationship with a correlation coefficient of 0.98 . The brittleness index $B_{2}$ and $K$ demonstrate a linear relationship with a correlation coefficient of 0.97 . The fitting results are overall satisfactory with clear data regularity. None of the selected functions adequately represent brittleness indexes $B_{3}$ and $B_{4}$ and $K$. The average value of $\alpha$ obtained from the tests is 7.899 , which is in good agreement with the Griffith constant $(\alpha=8)$.

4.2. Metamorphic Rock: Gneiss. Results of the gneiss mechanical parameters obtained from the laboratory test are

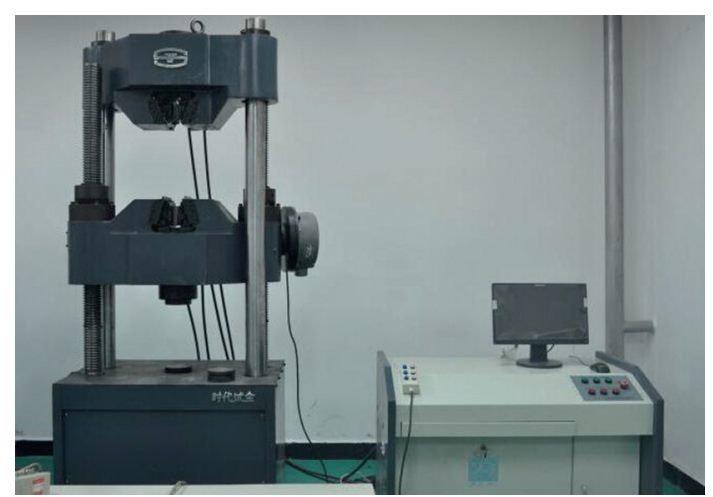

FIgURE 2: WAW-600C mechanical test equipment.

listed in Table 2. Figure 4 shows that brittleness index $B_{1}$ and $K$ display a power function relationship with a correlation coefficient of 0.91 , and $B_{2}$ and $K$ demonstrate a linear relationship with a correlation coefficient of 0.91 . As with granite, no functional relationship is observed between $B_{3}$ and $B_{4}$ and $K$. The average $\alpha$ value obtained from the tests is 7.856, which was also consistent with the Griffith constant $(\alpha=8)$. The results of these two tests verify that the Griffith crack model is suitable for brittle rock.

4.3. Sedimentary Rock: Limestone. Table 3 lists the limestone mechanical parameters acquired from the laboratory tests. Figure 5 shows that $B_{1}$ and $K$ have a power relationship with a correlation coefficient of $0.86, B_{2}$ and $K$ have a linear relationship with a correlation coefficient of 0.82 , and no functional relationship is observed between $B_{3}$ and $B_{4}$ and $K$. The interior of rocks for this group is well cemented by grains with moderate porosity $(5 \%-12 \%)$. The test results show that when the average $\sigma_{\mathrm{c}}$ is about $77 \mathrm{MPa}$, the average $\alpha$ obtained from this test group is 5647 .

\section{Discussion}

The experimental results for all rock types display a power relationship between $B_{1}$ and $K$, a linear relationship between $B_{2}$ and $K$, and no determinable relationship between $B_{3}$ and $B_{4}$ and $K$. The relationship between $B_{1}$ and $B_{2}$ and $K$ are therefore verified by experiments. We combine data from this study with results from Wang et al. [34] and Cai et al. [33] to further discuss the behavior of $B_{1}-B_{4}$ and $K$. Figure 6 shows that the fitted curves of $B_{1}$ and $K$ also yield a power function relationship with a correlation coefficient of 0.74. $B_{2}$ and $K$ demonstrate a linear function relationship with a correlation coefficient of 0.70 . As in the smaller data set, no functional relationship is detected between $B_{3}$ and $B_{4}$ and $K$. These results are consistent with those achieved from similar lithology, which indicates that this rule can be applied to all rocks, particularly those with higher homogeneity.

According to the test results shown in Figure $6, B_{1}$ and $B_{2}$ can be defined as 
TABLE 1: Summary of mechanical parameters of granite samples.

\begin{tabular}{lccccccccc}
\hline No. & $\sigma_{\mathrm{ci}}(\mathrm{MPa})$ & $\sigma_{\mathrm{c}}(\mathrm{MPa})$ & $\sigma_{\mathrm{t}}(\mathrm{MPa})$ & $\alpha$ & $\sigma_{\mathrm{ci}} / \sigma_{\mathrm{c}}$ & \multicolumn{3}{c}{ Brittleness index } \\
& & & & & $B_{1}$ & $B_{2}$ & $B_{3}$ \\
\hline H01 & 54.390 & 118.220 & 6.873 & 7.913 & 0.460 & 17.200 & 0.890 & 406.273 \\
H02 & 56.136 & 109.424 & 7.017 & 8.000 & 0.513 & 15.594 & 0.879 & 383.914 & 19.156 \\
H03 & 63.265 & 116.501 & 7.775 & 8.137 & 0.543 & 14.983 & 0.875 & 452.921 & 21.282 \\
H04 & 55.176 & 116.983 & 6.754 & 8.169 & 0.472 & 17.320 & 0.891 & 395.074 & 19.876 \\
H05 & 64.065 & 108.120 & 7.876 & 8.134 & 0.593 & 13.727 & 0.864 & 425.787 & 20.635 \\
H06 & 78.165 & 117.100 & 9.371 & 8.342 & 0.668 & 12.497 & 0.852 & 548.644 & 23.423 \\
H07 & 41.718 & 118.041 & 5.306 & 7.862 & 0.353 & 22.245 & 0.914 & 313.191 \\
H08 & 64.635 & 135.280 & 8.770 & 7.370 & 0.478 & 15.425 & 0.878 & 593.230 \\
H09 & 59.355 & 104.510 & 7.653 & 7.756 & 0.568 & 13.656 & 0.864 & 399.906 \\
H10 & 74.160 & 101.500 & 9.564 & 7.754 & 0.731 & 10.613 & 0.828 & 485.382 \\
H11 & 44.580 & 108.470 & 5.899 & 7.557 & 0.411 & 18.389 & 0.897 & 319.921 \\
H12 & 40.815 & 124.665 & 5.161 & 7.909 & 0.327 & 24.157 & 0.920 & 321.679 \\
H13 & 42.195 & 111.960 & 5.420 & 7.786 & 0.377 & 20.658 & 0.908 & 303.389 \\
\hline
\end{tabular}

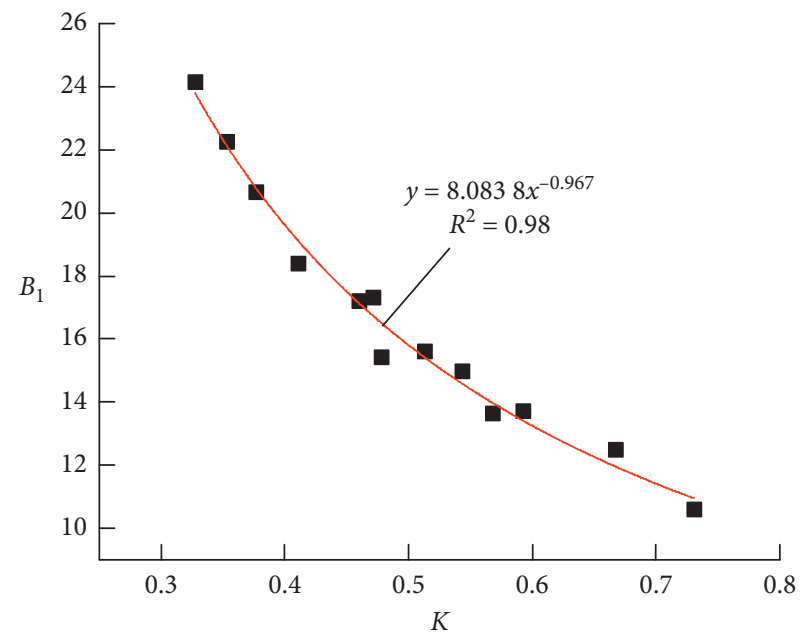

(a)

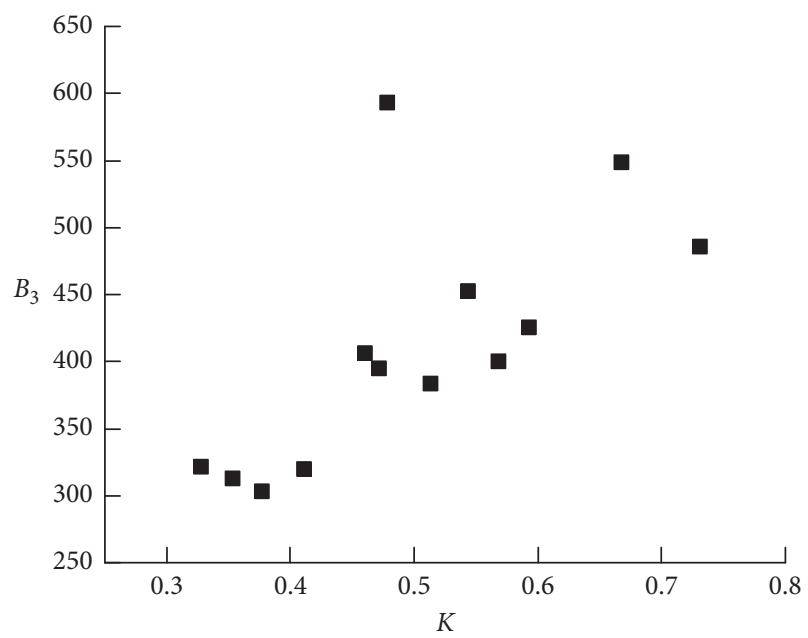

(c)

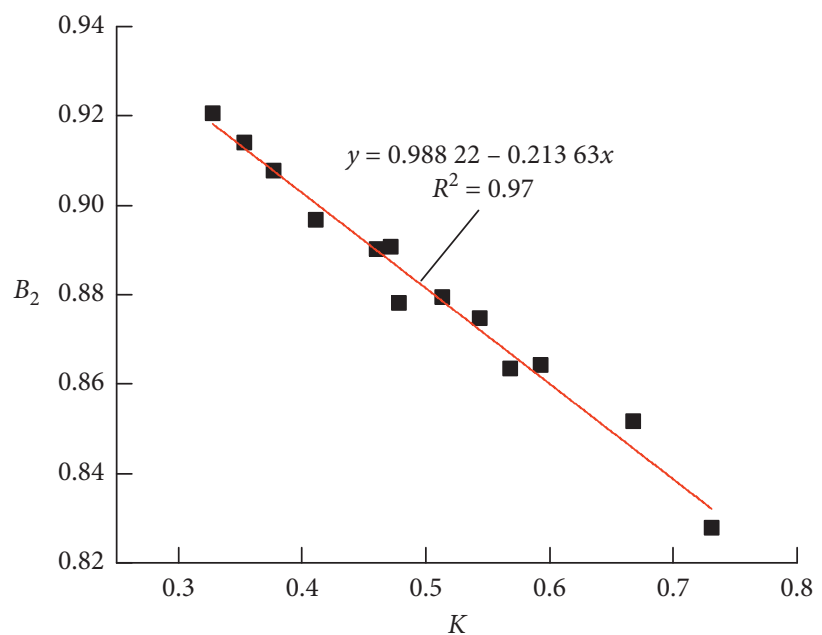

(b)

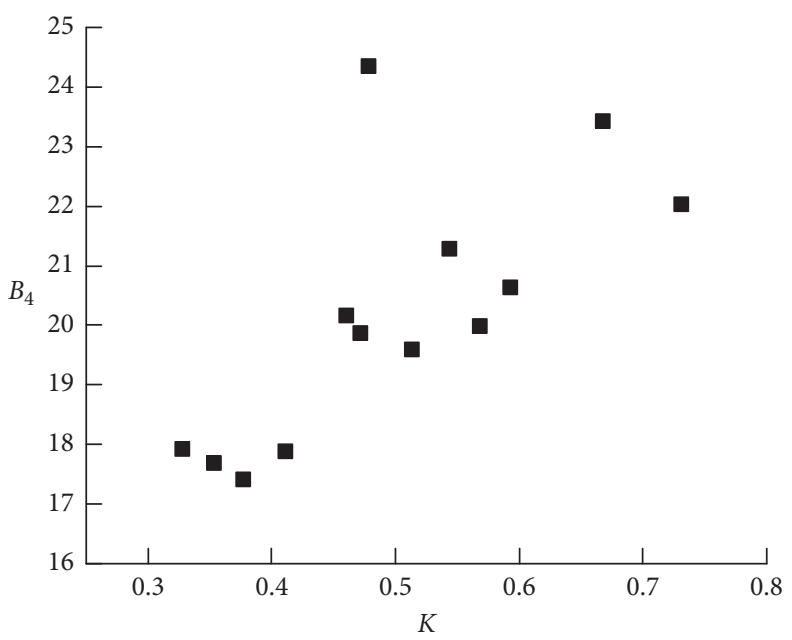

(d)

FIgURE 3: Relationship between crack initiation stress ratio $K$ of granite and different brittleness indexes: (a) $B_{1}$; (b) $B_{2}$; (c) $B_{3}$; (d) $B_{4}$. 
TABLE 2: Summary of mechanical parameters of gneiss samples.

\begin{tabular}{|c|c|c|c|c|c|c|c|c|c|}
\hline \multirow{2}{*}{ No } & \multirow{2}{*}{$\sigma_{\mathrm{ci}}(\mathrm{MPa})$} & \multirow{2}{*}{$\sigma_{\mathrm{c}}(\mathrm{MPa})$} & \multirow{2}{*}{$\sigma_{\mathrm{t}}(\mathrm{MPa})$} & \multirow{2}{*}{$\alpha$} & \multirow{2}{*}{$\sigma_{\mathrm{ci}} / \sigma_{\mathrm{c}}$} & \multicolumn{4}{|c|}{ Brittleness index } \\
\hline & & & & & & $B_{1}$ & $B_{2}$ & $B_{3}$ & $B_{4}$ \\
\hline P01 & 44.890 & 73.250 & 5.310 & 8.454 & 0.613 & 13.795 & 0.865 & 194.476 & 13.945 \\
\hline $\mathrm{P} 02$ & 41.260 & 68.740 & 6.086 & 6.780 & 0.600 & 11.295 & 0.837 & 209.169 & 14.463 \\
\hline P03 & 51.075 & 95.780 & 6.475 & 7.888 & 0.533 & 14.792 & 0.873 & 310.086 & 17.609 \\
\hline P04 & 35.250 & 68.130 & 4.343 & 8.117 & 0.517 & 15.689 & 0.880 & 147.928 & 12.163 \\
\hline P05 & 43.815 & 83.360 & 5.535 & 7.916 & 0.526 & 15.060 & 0.875 & 230.712 & 15.189 \\
\hline P06 & 40.230 & 79.630 & 5.226 & 7.699 & 0.505 & 15.238 & 0.877 & 208.058 & 14.424 \\
\hline P07 & 50.655 & 89.120 & 6.391 & 7.926 & 0.568 & 13.945 & 0.866 & 284.775 & 16.875 \\
\hline P08 & 41.625 & 99.600 & 5.551 & 7.499 & 0.418 & 17.943 & 0.894 & 276.439 & 16.626 \\
\hline P09 & 75.450 & 94.230 & 9.464 & 7.972 & 0.801 & 9.956 & 0.817 & 445.915 & 21.117 \\
\hline P10 & 44.010 & 72.400 & 5.658 & 7.779 & 0.608 & 12.797 & 0.855 & 204.803 & 14.311 \\
\hline P11 & 80.475 & 97.490 & 10.122 & 7.951 & 0.825 & 9.632 & 0.812 & 493.381 & 22.212 \\
\hline P12 & 70.725 & 103.530 & 8.769 & 8.066 & 0.683 & 11.807 & 0.844 & 453.908 & 21.305 \\
\hline P13 & 61.620 & 100.750 & 7.627 & 8.079 & 0.612 & 13.210 & 0.859 & 384.200 & 19.601 \\
\hline
\end{tabular}

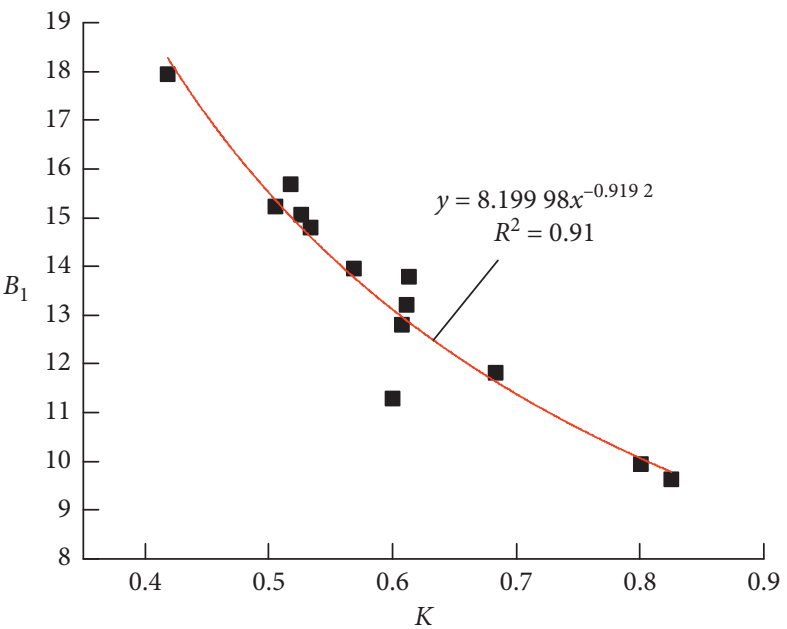

(a)

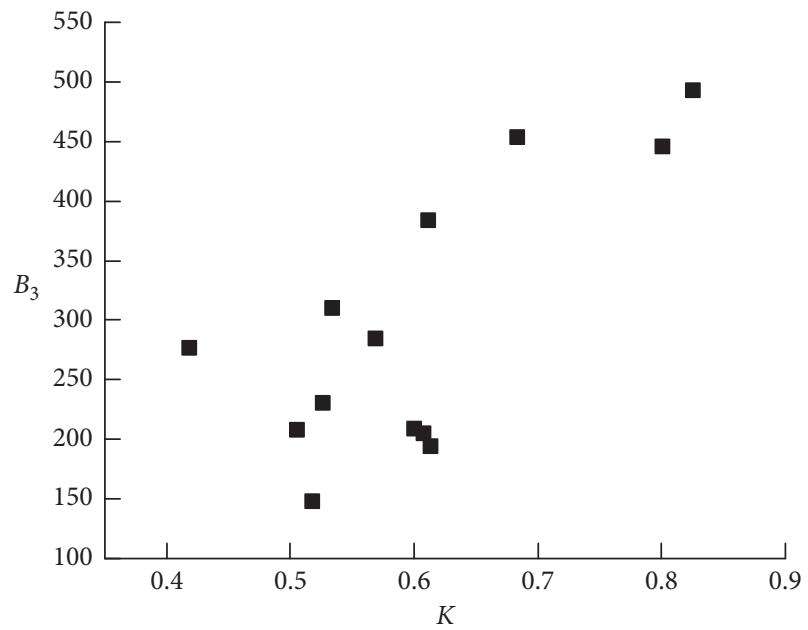

(c)

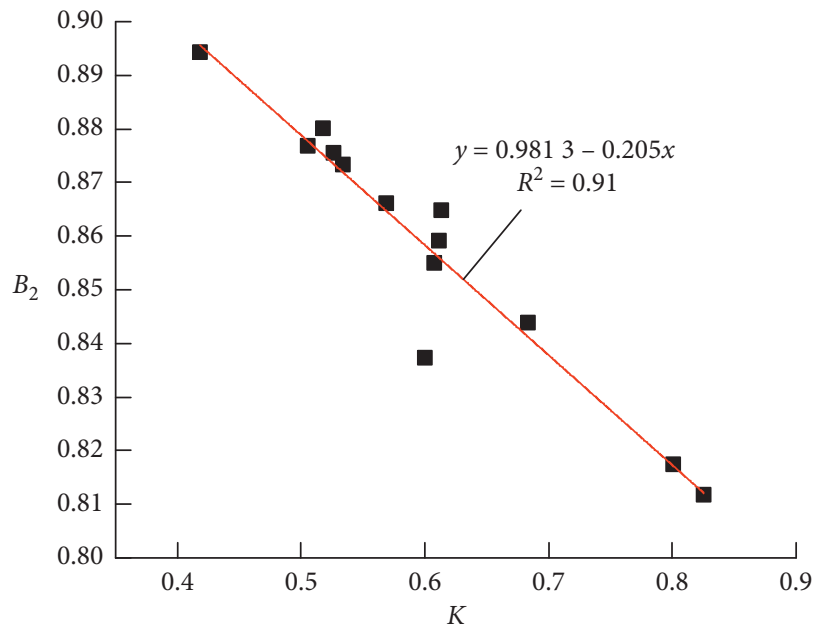

(b)

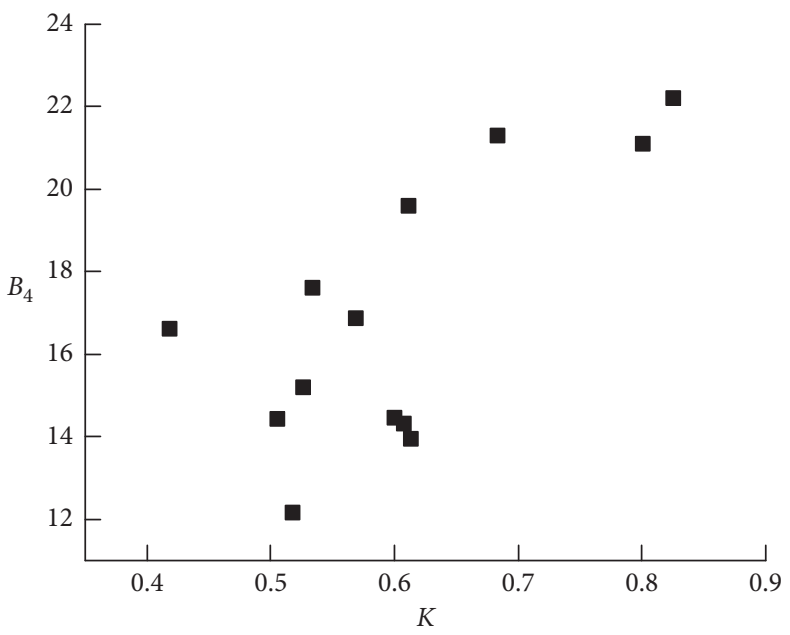

(d)

Figure 4: Relationship between crack initiation stress ratio $K$ of gneiss and different brittleness indexes: (a) $B_{1}$; (b) $B_{2}$; (c) $B_{3}$; (d) $B_{4}$. 
TABLE 3: Summary of mechanical parameters of limestone samples.

\begin{tabular}{|c|c|c|c|c|c|c|c|c|c|}
\hline \multirow{2}{*}{ No } & \multirow{2}{*}{$\sigma_{\mathrm{ci}}(\mathrm{MPa})$} & \multirow{2}{*}{$\sigma_{\mathrm{c}}(\mathrm{MPa})$} & \multirow{2}{*}{$\sigma_{\mathrm{t}}(\mathrm{MPa})$} & \multirow{2}{*}{$\alpha$} & \multirow{2}{*}{$\sigma_{\mathrm{ci}} / \sigma_{\mathrm{c}}$} & \multicolumn{4}{|c|}{ Brittleness index } \\
\hline & & & & & & $B_{1}$ & $B_{2}$ & $B_{3}$ & $B_{4}$ \\
\hline S01 & 46.560 & 75.600 & 8.700 & 5.352 & 0.616 & 8.690 & 0.794 & 328.860 & 18.134 \\
\hline S02 & 37.776 & 80.100 & 6.870 & 5.499 & 0.472 & 11.659 & 0.842 & 275.144 & 16.587 \\
\hline S03 & 54.096 & 89.300 & 9.620 & 5.623 & 0.606 & 9.283 & 0.805 & 429.533 & 20.725 \\
\hline S04 & 40.640 & 64.400 & 7.500 & 5.419 & 0.631 & 8.587 & 0.791 & 241.500 & 15.540 \\
\hline S05 & 33.072 & 84.600 & 6.540 & 5.057 & 0.391 & 12.936 & 0.856 & 276.642 & 16.633 \\
\hline S06 & 32.528 & 60.800 & 5.330 & 6.103 & 0.535 & 11.407 & 0.839 & 162.032 & 12.729 \\
\hline S07 & 56.960 & 78.700 & 9.030 & 6.308 & 0.724 & 8.715 & 0.794 & 355.331 & 18.850 \\
\hline S08 & 47.488 & 86.200 & 8.160 & 5.820 & 0.551 & 10.564 & 0.827 & 351.696 & 18.754 \\
\hline
\end{tabular}

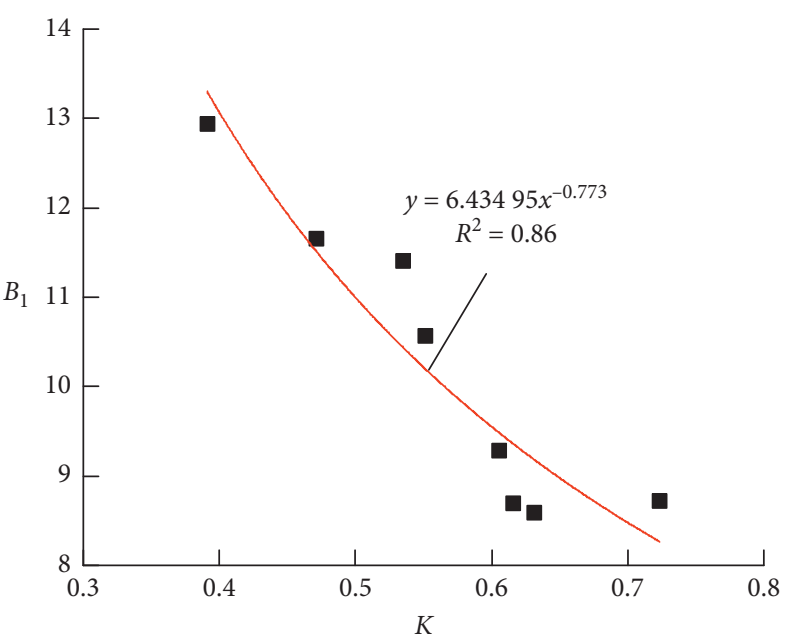

(a)

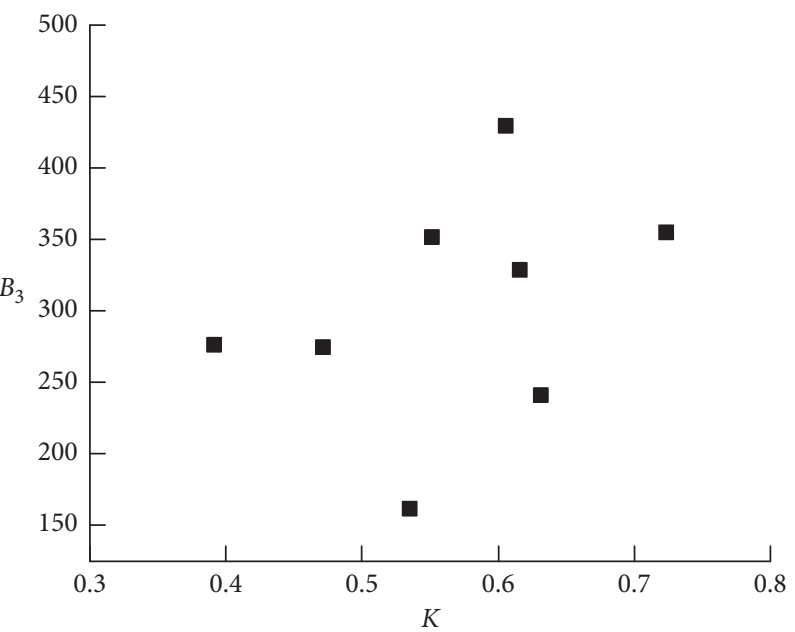

(c)

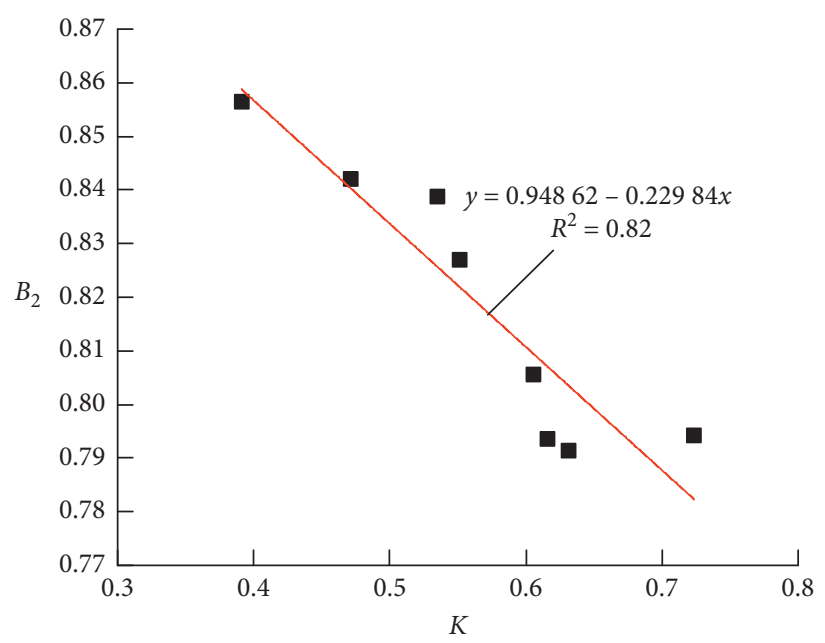

(b)

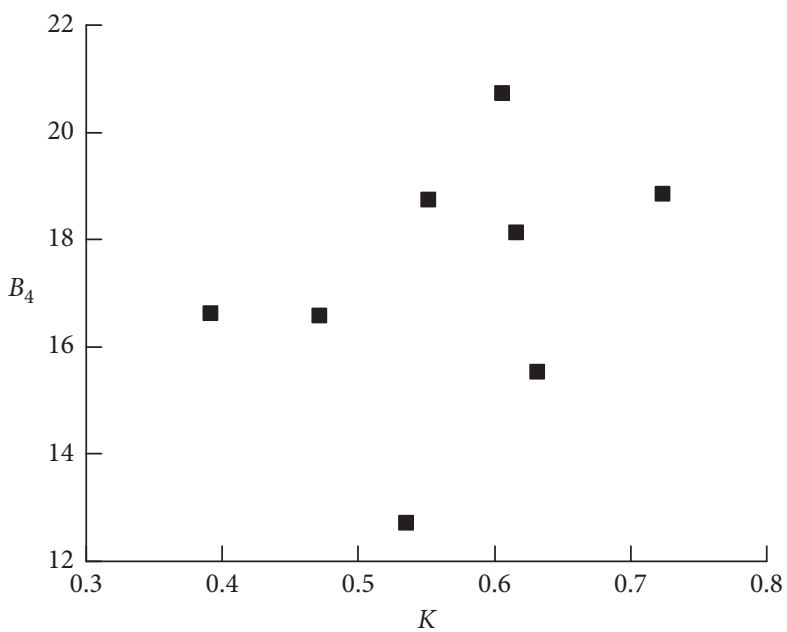

(d)

FiguRe 5: Relationship between crack initiation stress ratio $K$ of limestone and different brittleness indexes: (a) $B_{1}$; (b) $B_{2}$; (c) $B_{3}$; (d) $B_{4}$.

$$
\begin{aligned}
& B_{1}=a_{1} K^{b_{1}}, \\
& B_{2}=a_{2}+b_{2} K,
\end{aligned}
$$

where $a_{1}, a_{2}, b_{1}$, and $b_{2}$ are the fitting constants. In this paper, we have $a_{1}=7.024, a_{2}=0.9991, b_{1}=-1.054$, and $b_{2}=-0.258$.

We next gathered uniaxial compression test data of 127 different rock types from the literature [8,39-42], including
58 igneous rocks, 21 metamorphic rocks, and 48 sedimentary rocks. The data were fitted with equation (22) (method $1)$, equation $(24)(\operatorname{method} 2)$, and equation $(25)(\operatorname{method} 3)$ to predict $K$. Our experimental results yield $\alpha=8$ for both igneous and metamorphic rocks. However, the porosity of the sedimentary rock used in the experiments is moderate, and the tests show that the limestone $\sigma_{\mathrm{c}}$ is $75.05 \pm 14.25 \mathrm{MPa}$ and $\alpha=5$. The $\alpha$ value for sedimentary rocks is therefore 


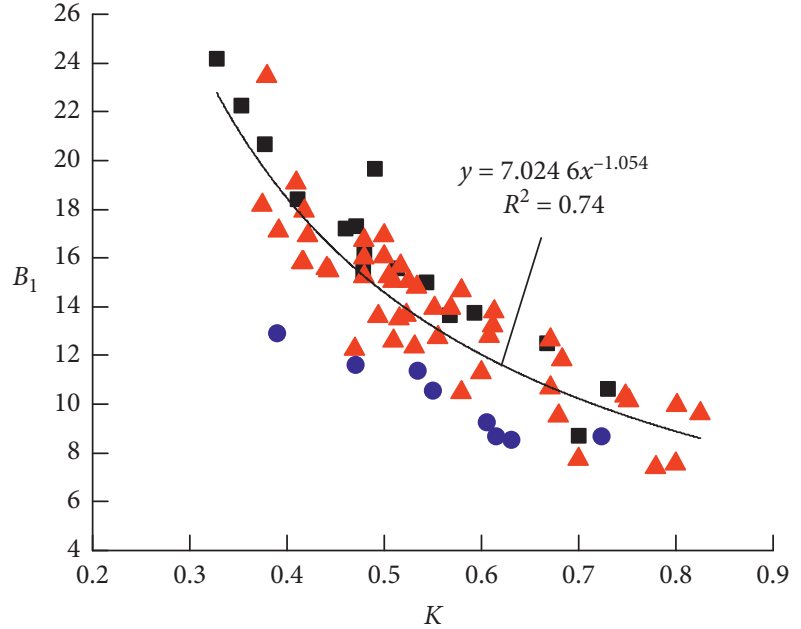

Igneous rock

- Metamorphic rock

- Sedimentary rock

(a)

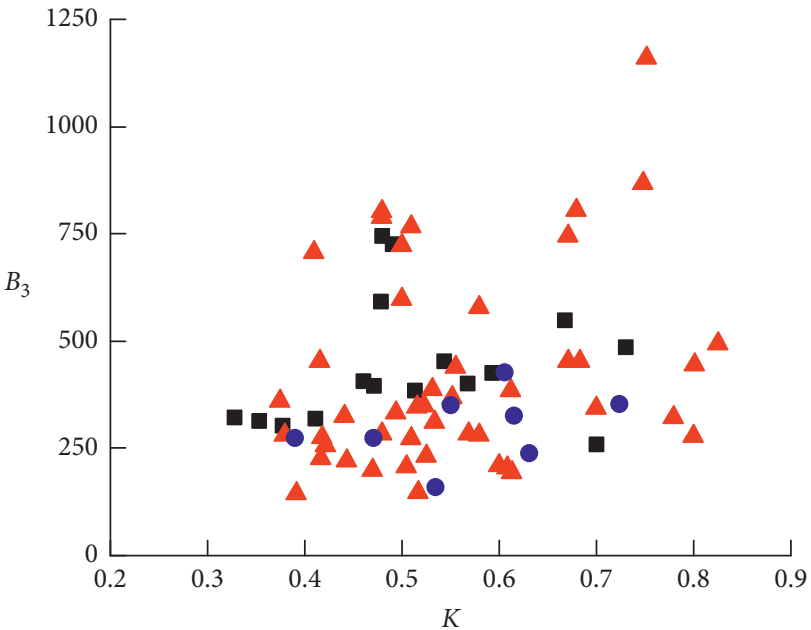

- Igneous rock

- Metamorphic rock

- Sedimentary rock

(c)

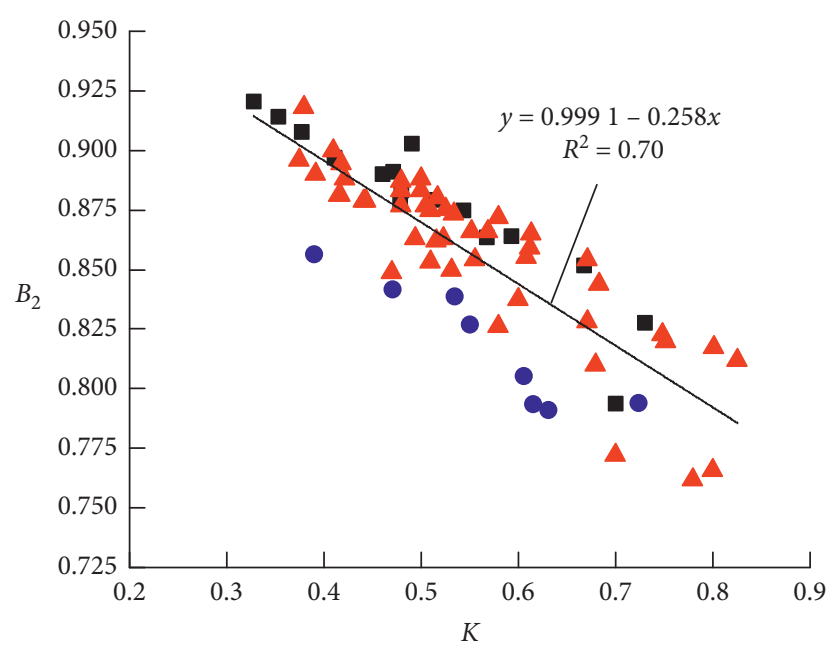

- Igneous rock

- Metamorphic rock

- Sedimentary rock

(b)

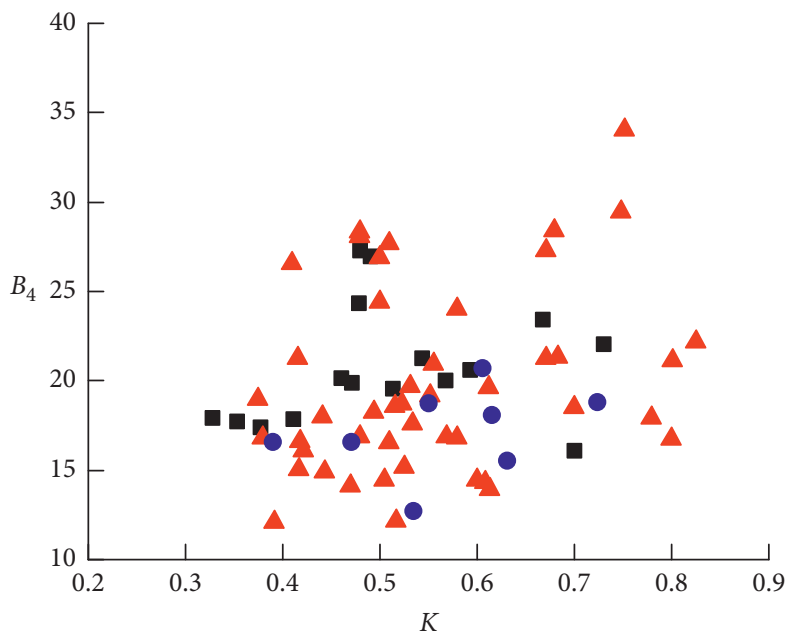

- Igneous rock

- Metamorphic rock

- Sedimentary rock

(d)

FIGURE 6: Relationship between crack initiation stress ratio $K$ and different rock types of rocks with different brittleness indexes: (a) $B_{1}$; (b) $B_{2}$; (c) $B_{3}$; (d) $B_{4}$.

temporarily set to 3 for $\sigma_{\mathrm{c}}<60 \mathrm{MPa}$ (high porosity), 5 for $60 \mathrm{MPa} \leq \sigma_{\mathrm{c}} \leq 90 \mathrm{MPa}$ (moderate porosity), and 8 for $\sigma_{\mathrm{c}}>90 \mathrm{MPa}$ (low porosity). A large number of additional experiments are required for the accurate determination of $\alpha$, which can be further explored in subsequent studies.

Figure 7 and Table 4 show that the $K$ values of igneous, metamorphic, and sedimentary rocks predicted by the three methods are all within reasonable ranges. Values of $K$ for igneous and metamorphic rocks obtained from the three methods are distributed over a relatively large range from 0.2 to 0.8 , among which $K$ for igneous rocks concentrate between 0.4 and 0.8 and $K$ for metamorphic rocks concentrate between 0.2 and 0.6 . In method $1, K$ values for sedimentary rocks are concentrated between 0.2 and 0.6 , while in methods 2 and 3, they concentrate between 0.4 and 0.8 . The three prediction methods present average $K$ values of 0.566 , 0.519 , and 0.511 , respectively, for igneous rocks. Similarly, the average $K$ values for metamorphic are $0.47,0.461$, and 0.454 , respectively, and those for sedimentary rocks are 0.37 , 0.604 , and 0.594 . The results are consistent with values reported by Wen Tao of $0.503,0.5396$, and 0.3759 for igneous, metamorphic, and sedimentary rocks, respectively. However, the average $K$ for sedimentary rocks obtained by the fitting methods differ slightly from the statistical experimental results. The primary cause of the differences is that the fitting of equations (24) and (25) can introduce 

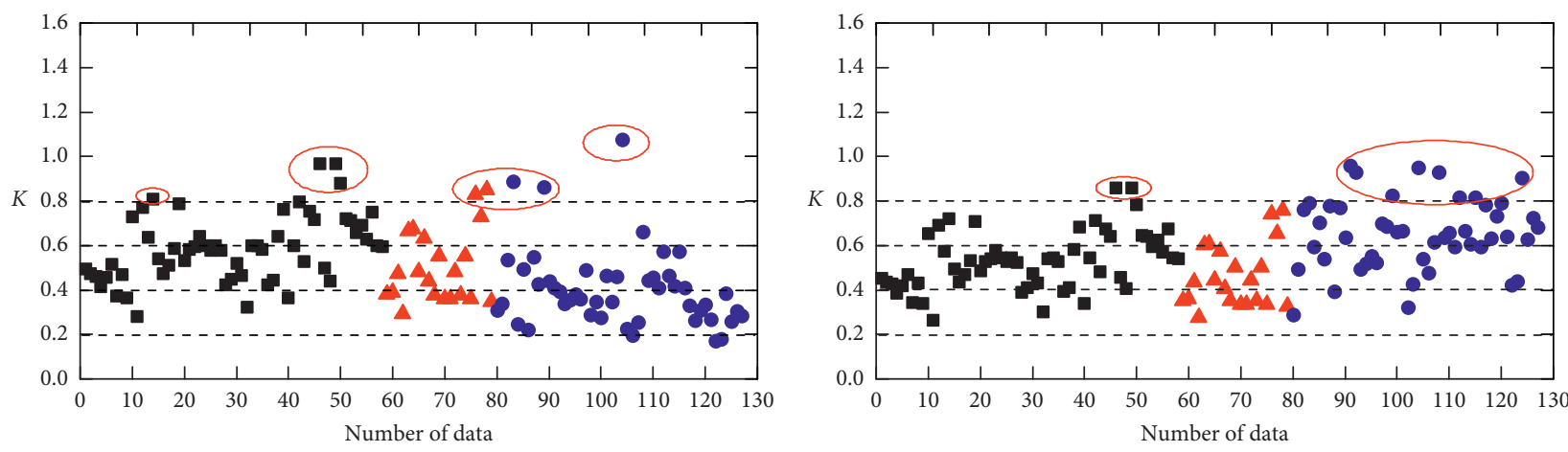

- Igneous rock

- Metamorphic rock

- Igneous rock

- Sedimentary rock

- Metamorphic rock

- Sedimentary rock

(a)

(b)

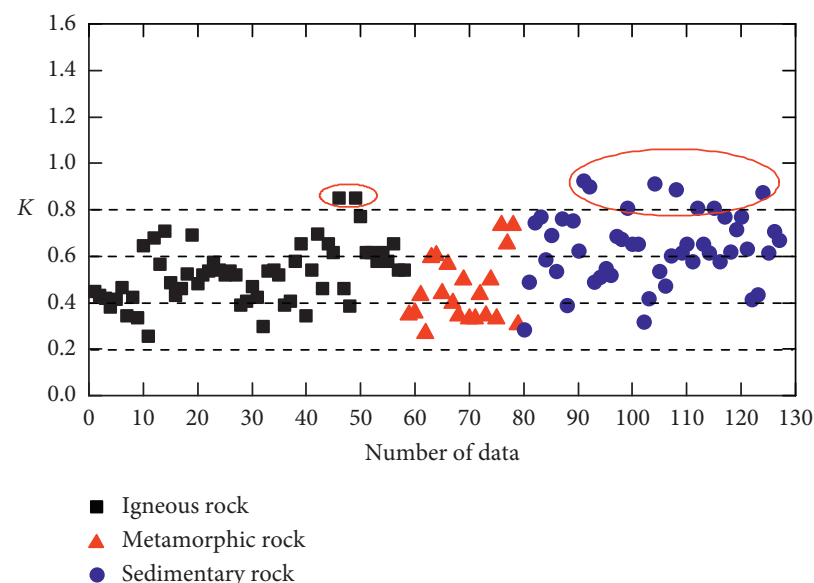

(c)

Figure 7: Prediction of $K$ value for igneous, metamorphic, and sedimentary rocks using (a) method 1, (b) method 2, and (c) method 3.

TABle 4: Percentage of $K$ value range distribution of different rock types under three prediction methods.

\begin{tabular}{lccccccccc}
\hline Method & \multicolumn{2}{c}{$\begin{array}{c}\text { Percentage of } K \text { value range } \\
\text { distribution of igneous rock (\%) }\end{array}$} & \multicolumn{2}{c}{$\begin{array}{c}\text { Percentage of } K \text { value range } \\
\text { distribution of metamorphic rock } \\
(\%)\end{array}$} & \multicolumn{3}{c}{$\begin{array}{c}\text { Percentage of } K \text { value range } \\
\text { distribution of sedimentary rock } \\
(\%)\end{array}$} \\
& $0.2 \sim 0.4$ & $0.4 \sim 0.6$ & $0.6 \sim 0.8$ & $0.2 \sim 0.4$ & $0.4 \sim 0.6$ & $0.6 \sim 0.8$ & $0.2 \sim 0.4$ & $0.4 \sim 0.6$ & $0.6 \sim 0.8$ \\
\hline 1 & 8.6 & 53.4 & 31 & 42.9 & 28.6 & 19 & 50 & 35.4 & 2.1 \\
2 & 13.8 & 60.3 & 22.4 & 42.9 & 33.3 & 23.8 & 6.25 & 29.2 & 47.9 \\
3 & 15.5 & 58.6 & 22.4 & 47.6 & 33.3 & 19 & 6.25 & 29.2 \\
\hline
\end{tabular}

errors owing to a lack of experimental data for sedimentary rocks. Additional experiments are therefore required to verify the fitting equations and further adjust $\alpha$. The above analysis clearly demonstrates that the presented equations for brittleness index can reliably predict $K$.

\section{Conclusions}

In this study, we determined the relationship between brittleness index and crack initiation stress ratio $(K)$ by fracture mechanics theory and indoor uniaxial compression tests. After theoretical derivation, the brittleness index $B_{1}$ is found to have an inversely proportional relationship with $K$ and brittleness index $B_{2}$ has a variant inverse proportional relationship with $K$, whereas no relationship is observed between brittleness indexes $B_{3}$ and $B_{4}$ and $K$. Analysis of experimental data from igneous, metamorphic, and sedimentary rocks shows that $B_{1}$ displays a power relationship with $K, B_{2}$ has a linear relationship with $K$, and no relationship is observed between $B_{3}$ and $B_{4}$ and $K$. Seventy different types of uniaxial compression test data were collected from igneous, metamorphic, and sedimentary rocks, and consistent behavior is observed within the same rock types.

The experimental data verify $K$ estimations based on Griffith's theory, and the constant $\alpha$ is temporarily specified 
on the basis of available experimental data. For example, $\alpha=8$ for igneous and metamorphic rocks, whereas sedimentary rocks were defined as (according to results of limestone tests) $\alpha=3$ when $\sigma_{\mathrm{c}}<60 \mathrm{MPa}$ (high porosity), $\alpha=5$ when $60 \mathrm{MPa} \leq \sigma_{\mathrm{c}} \leq 90 \mathrm{MPa}$ (moderate porosity), and $\alpha=8$ when $\sigma_{\mathrm{c}}>90 \mathrm{MPa}$ (low porosity). Further tests should be conducted to improve the determination of $\alpha$.

$K$ values were estimated on the basis of 127 uniaxial compression test data for different rock types. The results show that $K$ concentrates between 0.4 and 0.8 values for igneous rocks and between 0.2 and 0.6 for metamorphic rocks. In method $1, K$ values for sedimentary rocks concentrate between 0.2 and 0.6 , whereas methods 2 and 3 yield $K$ values between 0.4 and 0.8 . Average $K$ values for all rock types obtained by the three prediction methods are consistent with the experimental data. The redefined brittleness index formula can therefore be used for reliable predictions of $K$.

\section{Abbreviations}

$\mathrm{d} W_{\mathrm{r}}:$ Postpeak rupture energy $\left(\mathrm{kJ} \cdot \mathrm{m}^{-3}\right)$

$\mathrm{d} W_{\alpha}$ : Released elastic energy $\left(\mathrm{kJ} \cdot \mathrm{m}^{-3}\right)$

$M: \quad$ Postpeak modulus (GPa)

$E_{\mathrm{u}}$ : Unloading elastic modulus (GPa)

$\tau_{\mathrm{p}}$ : Peak strength (MPa)

$\tau_{\mathrm{r}}: \quad$ Residual strength $(\mathrm{MPa})$

$\varepsilon_{\mathrm{p}}$ : $\quad$ Peak strain (\%)

$\varepsilon_{\mathrm{r}}: \quad$ Residual strain (\%)

$\varepsilon_{\mathrm{h}}: \quad$ Reversible strain (\%)

$\varepsilon: \quad$ Total strain (\%)

$W_{\mathrm{r}}$ : Reversible strain energy $\left(\mathrm{kJ} \cdot \mathrm{m}^{-3}\right)$

$W: \quad$ Total strain energy $\left(\mathrm{kJ} \cdot \mathrm{m}^{-3}\right)$

$H_{\mu}$ : Microindentation hardness $\left(\mathrm{N} \cdot \mathrm{mm}^{-2}\right)$

$H: \quad$ Macroindentation hardness $\left(\mathrm{N} \cdot \mathrm{mm}^{-2}\right)$

E: Young's modulus (GPa)

$K_{\text {IC }}$ Fracture toughness $\left(\mathrm{MPa} \cdot \mathrm{m}^{-1 / 2}\right)$

$k: \quad$ Constant

$F_{\text {max }}$ : Maximum applied force on a rock sample $(\mathrm{kN})$

$P: \quad$ Corresponding penetration at maximum force $(\mathrm{mm})$

$P_{\mathrm{dec}}$ : Average force decrement period (s)

$P_{\text {inc }}$ : Average force increment period (s)

$\theta: \quad$ Internal friction angle $\left({ }^{\circ}\right)$

$S_{20}$ : Percentage of fines (\%)

$q$ : $\quad$ Percentage of fines formed in impact test (\%)

$\varepsilon_{\mathrm{cv}}: \quad$ Crack volume strain (\%)

$\varepsilon_{\mathrm{v}}$ : Total volume strain (\%)

$\varepsilon_{\mathrm{ev}}: \quad$ Elastic volume strain (\%)

$\varepsilon_{1}$ : Axial strain (\%)

$\varepsilon_{2}$ : Lateral strain (\%)

$v$ : Poisson's ratio

$\sigma_{\text {ci }}: \quad$ Crack initiation $(\mathrm{MPa})$

$\sigma_{\text {cd }}: \quad$ Crack damage $(\mathrm{MPa})$

$K$ : $\quad$ Crack initiation stress ratio

$\sigma_{\mathrm{t}}: \quad$ Tensile strength (TS) (MPa)

$\alpha$ : Constant

$a_{1}$ : Fitting constant

$a_{2}$ : Fitting constant

$b_{1}$ : $\quad$ Fitting constant $b_{2}$ : Fitting constant.

\section{Data Availability}

The data of this study are available from the corresponding author upon request.

\section{Conflicts of Interest}

The authors declare that they have no conflicts of interest.

\section{Acknowledgments}

This project was supported by the National Natural Science Foundation of China under Project nos. 51874160, LT2018008, and LR2016039.

\section{References}

[1] A. Morley, Strength of Materials, Longmans, London, UK, 11th edition, 1954.

[2] M. Hetenyi, Handbook of Experimental Stress Analysis, Wiley, New York, NY, USA, 1966.

[3] J. G. Ramsey, Folding and Fracturing of Rocks, McGraw-Hill, London, UK, 1967.

[4] L. Obert and W. I. Duvall, Rock Mechanics and the Design of Structures in Rock, Wiley, New York, NY, USA, 1967.

[5] V. Hucka and B. Das, "Brittleness determination of rocks by different methods," International Journal of Rock Mechanics and Mining Sciences \& Geomechanics Abstracts, vol. 11, no. 10, pp. 389-392, 1974.

[6] R. Altindag, "The evaluation of rock brittleness concept on rotary blast hole drills," Journal of the Southern African Institute of Mining and Metallurgy, vol. 102, no. 1, pp. 61-66, 2002.

[7] R. Altindag, "Correlation of specific energy with rock brittleness concepts on rock cutting," Journal of the Southern African Institute of Mining and Metallurgy, vol. 103, no. 3, pp. 163-171, 2003.

[8] R. Altindag, "Assessment of some brittleness indexes in rockdrilling efficiency," Rock Mechanics and Rock Engineering, vol. 43, no. 3, pp. 361-370, 2010.

[9] B. Tarasov and Y. Potvin, "Universal criteria for rock brittleness estimation under triaxial compression," International Journal of Rock Mechanics and Mining Sciences, vol. 59, pp. 57-69, 2013.

[10] A. W. Bishop, "Progressive failure with special reference to the mechanism causing it," in Proceedings of the Geotechnical Conference, vol. 2, pp. 142-150, Oslo, Norway, 1967.

[11] V. Hajiabdolmajid and P. Kaiser, "Brittleness of rock and stability assessment in hard rock tunneling," Tunnelling and Underground Space Technology, vol. 18, no. 1, pp. 35-48, 2003.

[12] M. Aubertin, D. E. Gill, and R. Simon, "On the use of the brittleness index modified (BIM) to estimate the post peak behavior or rocks," in Proceedings of the 1st North American Rock Mechanics Symposium, pp. 945-952, Austin, TX, USA, 1994.

[13] E. A. George, Brittle Failure of Rock Material-Test Results and Constitutive Models, August Aimé Balkema, Rotterdam, Netherlands, 1995.

[14] H. Honda and Y. Sanada, "Hardness of coal," Fuel, vol. 35, p. 451, 1956. 
[15] B. R. Lawn and D. B. Marshall, "Hardness, toughness and brittleness: an indentation analysis," Journal of American Ceramic Society, vol. 62, no. 7-8, pp. 347-350, 1979.

[16] J. B. Quinn and G. D. Quinn, "Indentation brittleness of ceramics: a fresh approach," Journal of Materials Science, vol. 32, no. 16, pp. 4331-4346, 1997.

[17] S. Yagiz, "An investigation on the relationship between rock strength and brittleness," in Proceedings of the 59th Geological Congress of Turkey, vol. 352, MTA General Directory Press, Ankara, Turkey, 2006.

[18] H. Copur, N. Bilgin, H. Tuncdemir et al., "A set of indices based on indentation test for assessment of rock cutting performance and rock properties," Journal of the South African Institute of Mining and Metallurgy, vol. 103, no. 9, pp. 589-599, 2003.

[19] O. T. Blindheim and A. Bruland, Boreability testing. Norwegian TBM tunneling, Norwegian Soil and Rock Engineering Association, Trondheim, Norway, 1998.

[20] M. M. Protodyakonov, "Mechanical properties and drillability of rocks," in Proceedings of the 5th Symposium on Rock Mechanics, University of Minnesota Press, Twin Cities, MI, USA, pp. 103-118, 1962.

[21] D. Lockner, "The role of acoustic emission in the study of rock fracture," International Journal of Rock Mechanics and Mining Sciences \& Geomechanics Abstracts, vol. 30, no. 7, pp. 883899, 1993.

[22] X. P. Zhou, H. Cheng, and Y. F. Feng, "An experimental study of crack coalescence behaviour in rock-like materials containing multiple flaws under uniaxial compression," Rock Mechanics and Rock Engineering, vol. 47, no. 6, pp. 1961-1986, 2014.

[23] X. P. Zhou, Y. J. Lian, L. N. Y. Wong, and F. Berto, "Understanding the fracture behavior of brittle and ductile multiflawed rocks by uniaxial loading by digital image correlation," Engineering Fracture Mechanics, vol. 199, pp. 438-460, 2018.

[24] X.-P. Berto, Y.-T. Wang, J.-Z. Zhang, and F.-N. Liu, "Fracturing behavior study of three-flawed specimens by uniaxial compression and 3D digital image correlation: sensitivity to brittleness," Rock Mechanics and Rock Engineering, vol. 52, no. 3, pp. 691-718, 2019.

[25] J. Z. Liu, X. P. Zhou, L. S. Zhou, and F. Berto, "Progressive failure of brittle rocks with non-isometric flaws: insights from acousto-optic-mechanical (AOM) data," Fatigue \& Fracture of Engineering Materials \& Structures, vol. 42, no. 8, pp. 1787-1802, 2019.

[26] D. Huang and X. Q. Li, "Numerical simulation research on characteristic strength of marble based on development of microcrack," Rock and Soil Mechanics, vol. 38, no. 1, pp. 253-262, 2017, in Chinese.

[27] J.-m. Xu, F. Liu, Z.-y. Chen, and Y.-j. Wu, "Digital features of main constituents in granite during crack initiation and propagation," Engineering Geology, vol. 225, pp. 96-102, 2017.

[28] S.-Q. Wu, Y.-H. Huang, W.-L. Tian, and J.-B. Zhu, “An experimental investigation on strength, deformation and crack evolution behavior of sandstone containing two oval flaws under uniaxial compression," Engineering Geology, vol. 217, pp. 35-48, 2017.

[29] X.-P. Zhu, J.-Z. Zhang, Q.-H. Qian, and Y. Niu, "Experimental investigation of progressive cracking processes in granite under uniaxial loading using digital imaging and AE techniques," Journal of Structural Geology, vol. 126, pp. 129-145, 2019.
[30] C. D. Martin, "The strength of massive Lac du Bonnet granite around underground opening," $\mathrm{Ph}$. D. thesis, University of Manitoba, Winnipeg, Canada, 1993.

[31] M. Cai, P. K. Kaiser, Y. Tasaka, T. Maejima, H. Morioka, and M. Minami, "Generalized crack initiation and crack damage stress thresholds of brittle rock masses near underground excavations," International Journal of Rock Mechanics and Mining Sciences, vol. 41, no. 5, pp. 833-847, 2004.

[32] T. Niu, H. Tang, J. Ma, and Y. Wang, "Evaluation of methods for determining crack initiation stress under compression," Engineering Geology, vol. 235, pp. 81-97, 2018.

[33] M. Cai, "Practical estimates of tensile strength and HoekBrown strength parameter $m_{i}$ of brittle rocks," Rock Mechanics and Rock Engineering, vol. 43, no. 2, pp. 167-184, 2010.

[34] Y. Wang, X. Li, Y. F. Wu et al., "Research on relationship between crack initiation stress level and brittleness indices for brittle rocks," Chinese Journal of Rock Mechanics and Engineering, vol. 33, no. 2, pp. 264-275, 2014, in Chinese.

[35] A. Coviello, R. Lagioia, and R. Nova, "On the measurement of the tensile strength of soft rocks," Rock Mechanics and Rock Engineering, vol. 38, no. 4, pp. 251-273, 2005.

[36] C. D. Martin and G. W. Lanyon, EDZ in Clay Shale: Mont Terri, GeoScience Ltd, Falmouth, UK, 2001.

[37] B. J. Carter, E. J. Scott Duncan, and E. Z. Lajtai, "Fitting strength criteria to intact rock," Geotechnical and Geological Engineering, vol. 9, no. 1, pp. 73-81, 1991.

[38] J. C. Jaeger and N. G. W. Cook, Fundamentals of Rock Mechanics, Chapman-Hall and Science, London, UK, 1979.

[39] M. K. Özfırat, H. Yenice, F. Şimşir, and O. Yarale, "A new approach to rock brittleness and its usability at prediction of drillability," Journal of African Earth Sciences, vol. 119, pp. 94-101, 2016.

[40] C. J. Fan, S. Li, D. Elsworth, J. Han, and Z. Yang, "Experimental investigation on dynamic strength and energy dissipation characteristics of gas outburst-prone coal," Energy Science \& Engineering, vol. 8, no. 4, pp. 1015-1028, 2019.

[41] B. J. Huo, D. Jing, Y. L. Fan, and O. Han, "Numerical investigation of flue gas injection enhanced underground coal seam gas drainage," Energy Science \& Engineering, vol. 7, no. 6, pp. 3204-3219, 2019.

[42] C. J. Fan, M. K. Luo, S. Li, H. Zhang, Z. Yang, and Z. Liu, “A thermo-hydro-mechanical-chemical coupling model and its application in acid fracturing enhanced coalbed methane recovery simulation," Energies, vol. 12, no. 4, p. 626, 2019. 